\title{
円錐形ノズル内での定常粘性流動*
}

岡

小 天**

\section{The Steady Flow of a Viscous Fluid through a Conical Nozzle}

\author{
by \\ Syoten OKA \\ (Department of Physics, Tokyo Metropolitan University, Setagaya-ku, Tokyo)
}

The purpose of this paper is to present a theory of the steady flow of Newtonian liquid through a conical nozzle. The equation of motion of viscous liquid has been treated on the following assumptions : i) the liquid is incompressible ; ii) the motion of liquid is not turbulent; iii) the motion is steady; iv) no body force acts on the liquid; v) the motion has an axial symmetry; vi) there is no slip at the wall; vii) the stream lines are the straight lines passing through the vertex of the cone, that is, the end effect is neglected; viii) the motion is so slow that the inertia term can be neglected.

We have taken a spherical coordinate system $r, \theta$, and $\phi$ whose origin is at the vertex of the cone. Then the velocity is given by

$$
v_{r}=3 A(\cos 2 \theta-\cos 2 \alpha) / 4 r^{2},
$$

where $\alpha$ is the semi-angle of the cone, and $A$ is a constant. The expression for the pressure is obtained as follows:

$$
p=p_{0}+\frac{3}{2} A \gamma\left[\frac{\cos 2 \theta+1 / 3}{r^{3}}-\frac{\cos 2 \alpha+1 / 3}{r_{1}{ }^{3}}\right]
$$

where $\eta$ is the coefficient of viscosity, and $p_{0}$ the atmospheric pressure. Thus the average pressure gradient taken over the spherical surface of radius $r$ is given by

$$
\overline{\left(\frac{\partial p}{\partial r}\right)}=-\frac{3}{2} \frac{A n}{r^{4}}\left(2+\cos \alpha+\cos ^{2} \alpha\right) \text {. }
$$

On the other hand, the volume of flow in unit time is given by

$$
Q=-\pi A(1-\cos \alpha)^{2}(1+2 \cos \alpha) \text {. }
$$

Eliminating $A$ from the above two equations, we get

$$
Q=\frac{\pi}{8} \frac{R^{4}}{\eta} \overline{\left(\frac{\partial p}{\partial r}\right)} F(\alpha),
$$

where $R$ is equal to $r \alpha$, and $F(\alpha)$ is given by

$$
F(\alpha)=\frac{16}{3} \frac{(1-\cos \alpha)^{2}(1+2 \cos \alpha)}{\alpha^{4}\left(2+\cos \alpha+\cos ^{2} \alpha\right)} .
$$

Since $\lim _{\alpha \rightarrow 0} F(\alpha)=1$, the above equation may be reduced to Poiseuille's equation for a tube of uniform cross section.

From the expression for the velocity $v_{r}$ we can calculate stress components of the fluid. Especially, the tangential stress $\sigma_{r \theta}$ is given by

$$
\sigma_{r \theta}=-\frac{3}{2} A \eta \frac{\sin 2 \theta}{r^{3}} \text {. }
$$

For a given value of $r, \sigma_{r \theta}$ varies as $\sin \theta$ does in contrast with the case of a tube of uniform cross section where tangential stress decreases linearly from a maximum to zero with decreasing distance from the axis of the tube.

(Received Jan. 18, 1963)

\section{1. は しがき}

太さが一様な円管内の定常粘性流動に対しては有名

* 原稿受付 昭和38年 1 月 18 日

** 東京都立大学理学部
なポアズイユの法則が知られており，また2枚の傾い た平面壁の間の二次元的な定常粘性流動に対しては Rosenhead の計算がある.しかし円錐形ノズル内で の定常粘性流動はまだ理論的に取り扱われていない. 
ポアズイユの流れでは, 速度こう配は半径方向に対し て直線的に变化する。すなわち, 接線応力は管壁で最 大值をとり，直線的に減少して軸上で最小値零となる． このことは高分子溶液の場合, 管壁では分子の配向は よいが, 軸に近づくに従いしだいに配向が悪くなるこ とを意味する。そこで一様な円管の代わりに円錐形， ズル内での定常粘性流動を考光, 接線応力の分布が円 錐の半頂角とともにいかに変わるかを理論的に調べた. さらに流量を計算し，ポアズイ二の式に相当する式を 導いた。

\section{2. 仮定}

簡単のために液体としてはニニートン液体をとり， かつ次の諸仮定をする。ｉ）液体は非圧縮性である。

ii）流れは層流である，iii）流れは定常流である。

iv）液体に外力は働かない，V）流れは軸対称些をも っている.vi）管壁上では流速は零である、vii）ノズ ルの両端の影響が無視できるような範囲内のノズルの 部分だけを考え, 流線は円錐の頂点を通る直線群で与 えられるものとする。viii）流れは充分にのろくて慣 性項は無視できるものとし, Stokes 近似をとる.

\section{3. 運動方程式}

円錐の頂点を原点とする球座標 $r, \theta, \phi$ をとる。 ず連続の方程式は

$$
\frac{D \rho}{D t}+\rho \operatorname{div} \boldsymbol{v}=0
$$

$\rho$ は密度, $\boldsymbol{v}$ は速度である. 仮定 1)により $\rho=$ const. であるから

$$
\operatorname{div} \boldsymbol{v}=0
$$

仮定 $\mathrm{v})$, vii)により $v_{\theta}=v_{\phi}=0$ であるから，(2)は

$$
\frac{1}{r^{2}} \frac{\partial}{\partial r}\left(r^{2} v_{r}\right)=0
$$

一般に Navier-Stokes の運動方程式は

$$
\frac{\partial \boldsymbol{v}}{\partial t}+(\boldsymbol{v} \cdot \nabla) \boldsymbol{v}=K-\frac{1}{\rho} \operatorname{grad} p+\frac{1}{3} \nu \operatorname{grad} \operatorname{div} \boldsymbol{v}+\nu \Delta \boldsymbol{v}
$$

$p$ は圧力, $K$ は単位質量に働く外力, $\nu$ は運動学的粘 性率で, 粘性率クを密度 $\rho$ で割ったものである. 仮定 i ) v), vii), viii)により(4)は

$$
\begin{aligned}
& \frac{\partial p}{\partial r}=\eta\left(\nabla^{2} v_{r}-\frac{2 v_{r}}{r^{2}}\right) \\
& \frac{\partial p}{\partial \theta}=\eta \frac{2}{r} \frac{\partial v_{r}}{\partial \theta}
\end{aligned}
$$

ただし

$$
\nabla^{2}=\frac{1}{r^{2}} \frac{\partial}{\partial r}\left(r^{2} \frac{\partial}{\partial r}\right)+\frac{1}{r^{2} \sin \theta} \frac{\partial}{\partial \theta}\left(\sin \theta \frac{\partial}{\partial \theta}\right)
$$

(3)から

$$
\text { 4. 速度分布 }
$$

$$
v_{r}=f(\theta) / r^{2}
$$

ここに $f(\theta)$ は $\theta$ だけの関数である. (8)を $(5),(6)$ に入れ,さらに両式から $p$ を消去すれば

$$
\frac{d}{d \theta}\left[\frac{1}{\sin \theta} \frac{d}{d \theta}\left(f^{\prime} \sin \theta\right)\right]+6 f^{\prime}=0
$$

$\theta$ について積分すれば

$$
\frac{1}{\sin \theta} \frac{d}{d \theta}\left(f^{\prime} \sin \theta\right)+6 f=C
$$

Cは積分定数である。ここで

$$
x=\cos \theta
$$

とおけば, (10)は

$$
\left(1-x^{2}\right) \frac{d^{2} f}{d x^{2}}-2 x \frac{d f}{d x}+6 f=C
$$

となる。これの一般解は $A, B$ を定数として

$$
f=A P_{2}(x)+B Q_{2}(x)+\frac{C}{6}
$$

$P_{2}(x)$ は 2 次の第 1 種ルジャンドル関数, $Q_{2}(x)$ は 2 次 の第 2 種ルジ+ンドル関数で, それぞれ次式で定義さ れる。

$$
\begin{gathered}
P_{2}(x)=\frac{1}{2}\left(3 x^{2}-1\right) \\
Q_{2}(x)=\frac{1}{4}\left(3 x^{2}-1\right) \log \left|\frac{x-1}{x+1}\right|-\frac{3}{2} x
\end{gathered}
$$

$v_{r}$ は円錐の軸上で有限でなければならないから, $B=0$. したがって

$$
f=\frac{A}{2}\left(3 \cos ^{2} \theta-1\right)+\frac{1}{6} C
$$

円錐形ノズルの半頂角を $\alpha$ で表わせば，仮定 vi）によ り $f(\alpha)=0$ となる。これを満たすようにCを定めれば

$$
f=\frac{3}{4} A(\cos 2 \theta-\cos 2 \alpha)
$$

したがって

$$
v_{r}=\frac{3}{4} A \frac{1}{r^{2}}(\cos 2 \theta-\cos 2 \alpha)
$$

$$
\text { 5. 圧力分布 }
$$

(18)を（6）に入れて $\theta$ で積分すれば

$$
p=\frac{3}{2} A \eta \frac{1}{r^{3}} \cos 2 \theta+\phi(r)
$$

これを(5)に入れると

$$
\phi^{\prime}(r)=-\frac{3}{2} A \eta \frac{1}{r^{4}}
$$

したがって

$$
\psi(r)=\frac{1}{2} A \eta \frac{1}{r^{3}}+\text { const. }
$$

ゆえに

$$
p=\frac{3}{2} A \eta \frac{1}{r^{3}}\left(\cos 2 \theta+\frac{1}{3}\right)+\cos n t .
$$

ノズルの下端 $r=r_{1}$ での表面圧は一定 (大気圧) $p_{0}$ と みなしてよいから

$$
p_{0}=\frac{3}{2} A \eta \frac{1}{r_{1}^{3}}\left(\cos 2 \alpha+\frac{1}{3}\right)+\text { const. }
$$

したがって

$$
p=p_{0}+\frac{3}{2} A r_{1}\left[\frac{\cos 2 \theta+1 / 3}{r^{3}}-\frac{\cos 2 \alpha+1 / 3}{r_{1}{ }^{3}}\right]
$$




\section{6. 压力分 布}

一般に応力成分は次式で与えられる。

$$
\begin{aligned}
& \sigma_{r r}=-p+2 \eta \frac{\partial v_{r}}{\partial r} \\
& \sigma_{\theta \theta}=-p+2 \eta\left(\frac{1}{r} \frac{\partial v_{\theta}}{\partial \theta}+\frac{v_{r}}{r}\right) \\
& \sigma_{\phi \phi}=-p+2 \eta\left(\frac{1}{r \sin \theta} \frac{\partial v_{\phi}}{\partial \phi}+\frac{v_{r}}{r}+\frac{v_{\theta} \cot \theta}{r}\right) \\
& \sigma_{r \theta}=\eta\left(\frac{1}{r} \frac{\partial v_{r}}{\partial \theta}+\frac{\partial v_{\theta}}{\partial r}-\frac{v_{\theta}}{r}\right) \\
& \sigma_{\theta \phi}=\eta\left(\frac{1}{r \sin \theta} \frac{\partial v_{\theta}}{\partial \phi}+\frac{1}{r} \frac{\partial v_{\phi}}{\partial \theta}-\frac{v_{\phi} \cot \theta}{r}\right) \\
& \sigma_{\phi r}=\eta\left(\frac{\partial v_{\phi}}{\partial r}+\frac{1}{r \sin \theta} \frac{\partial v_{r}}{\partial \phi}-\frac{v_{\phi}}{r}\right)
\end{aligned}
$$

これらの式に $(18),(22)$ を入れる

$$
\begin{gathered}
\sigma_{r r}=-p_{0}-\frac{3}{2} A \eta\left[\frac{3 \cos 2 \theta+1 / 3-2 \cos 2 \alpha}{r^{3}}\right. \\
\left.-\frac{\cos 2 \alpha+1 / 3}{r_{1}{ }^{3}}\right] \\
\sigma_{\theta \theta}=\sigma_{\phi \phi}=-p_{0}-\frac{3}{2} A \eta\left[\frac{\cos 2 \alpha+1 / 3}{r^{3}}-\frac{\cos 2 \alpha+1 / 3}{r_{1}{ }^{3}}\right] \\
\sigma_{r \theta}=-\frac{3}{2} A \eta \frac{1}{r^{3}} \sin 2 \theta \\
\sigma_{\theta \phi}=\sigma_{\phi r}=0
\end{gathered}
$$

接線応力 $\sigma_{r \theta}$ は $\sin 2 \theta$ のように变わるので, 接線応 力の分布は一様な円管の場合に比べてやや内部まで一 様になる傾向がみられる。

\section{7. 流}

いま $r=r$ なる任意の球面を通って単位時間に流れ る液体の体積を $Q$ とすれば,

$$
Q=\iint\left(-v_{r}\right) r^{2} \sin \theta d \theta d \phi
$$

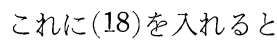

$$
\begin{aligned}
Q & =-\frac{3 \pi}{2} A \int_{0}^{\alpha}(\cos 2 \theta-\cos 2 \alpha) \sin \theta d \theta \\
\therefore \quad Q & =-\pi A(1-\cos \alpha)^{2}(1+2 \cos \alpha)
\end{aligned}
$$

(22)から，圧力こう配は

$$
\frac{\partial p}{\partial r}=-\frac{9}{2} \frac{A \eta}{r^{4}}\left(\cos 2 \theta+\frac{1}{3}\right)
$$

したがって, 球面上での平均をとれば

$$
\left(\frac{\overline{\partial p}}{\partial r}\right)=-\frac{3}{2} \frac{A \eta}{r^{4}}\left(2+\cos \alpha+\cos ^{2} \alpha\right)
$$

(28)と $(30)$ とからAを消去すれば

$$
Q=\frac{\pi}{8} \frac{R^{4}}{\eta} \overline{\left(\frac{\partial p}{\partial r}\right)} F(\alpha)
$$

ただし

$$
R=r \alpha
$$

とおいた。 $F(\alpha)$ は次式で与えられる。

$$
F(\alpha)=\frac{16}{3} \frac{(1-\cos \alpha)^{2}(1+2 \cos \alpha)}{\alpha^{4}\left(2+\cos \alpha+\cos ^{2} \alpha\right)}
$$

$\alpha \rightarrow 0$ の極限では

$$
\lim _{\alpha \rightarrow 0} F(\alpha)=1
$$

したがって，(31)はポアズイ二の法則と一致する。わ れわれが取り扱っているようなのろい運動においても， 一様な細管に対してポアズイユの法則が成り立つのは 当然である.

\section{8.おおりに}

以上の解析からわかるように, 円錐形ノズル内での 定常ニュートン流動では，接線応力は $\sin 2 \theta$ のように 変わり, 一様な円管の場合に比べてやや内部まで一様 になる傾向がみられる，流量に対してはポアズイユの 式に相当する式が導かれ，これは $\alpha \rightarrow 0$ なる極限でポ アズイユの式と一致する.

上の取り扱いは Stokes 近似に基づいており, 慣性 項を考虑に入れた取り披いが望まれる。ささらに非二ュ 一トン流動に対する計算も今後の問題である.

この問題を提示され, 研究を激励された呉祐吉教授 および有益な討論をされた山本三三三氏に厚く感謝の 意を表する。

\section{参考文 献}

1) L. Rosenhead, Proc. Roy. Soc. A, 436 (1940) 